\title{
Challenges of Flow Theory Applied to Computers in Education
}

\author{
Wilk Oliveira dos Santos ${ }^{1}$, Ig Ibert Bittencourt ${ }^{1}$, Seiji Isotani ${ }^{2}$, Ismar Frango \\ Silveira $^{3}$ Leonardo Brandão Marques ${ }^{2}$ \\ ${ }^{1}$ Center of Excellence for Social Technologies (NEES) - Computer Institute - Federal \\ University of Alagoas (IC-UFAL) Av. Lourival Melo Mota, S/N - Tabuleiro dos \\ Martins, CEP 57072-900 - Maceió - AL - Brazil \\ ${ }^{2}$ Computers in Education Laboratory (CAED) - Institute of Mathematics and Computer \\ Science - University of São Paulo (ICMC-USP) Av. Trabalhador São-carlense, 400 - \\ Centro - CEP 13566-590 - Carlos - SP - Brazil \\ ${ }^{3}$ Computers and Informatics Faculty - Mackenzie Presbyterian University (FCI-UPM) \\ R. da Consolação, 930 - Consolação - CEP 01302-907 - São Paulo - SP - Brazil \\ \{wos, ig.ibert\}@ic.ufal.br, sisotanidicmc.usp.br, \\ ismar.silveira@mackenzie.br, leobmarques@usp.br
}

\begin{abstract}
Flow Theory has been discussed in several aspects in the last decades, in domains such as: work, social life and education, among others. Particularly in the field of educational technology, a series of discussions have been conducted in the academia, bringing out some issues such as: the importance of flow state for education to develop didactic materials which could lead students to the flow state and better learning. In this sense, this paper has the goal of presenting to the community four contemporary challenges of Flow Theory applied to Computers in Education.
\end{abstract}

Resumo. A Teoria do Fluxo tem sido discutida em diversos aspectos nas ultimas décadas, em domínios como: trabalho, vida social e educação, entre outros. Na educação especificamente, uma serie de discussões tem permeado o cenário acadêmico, como: a importância do estado de fluxo na educação, o desenvolvimento de materiais didáticos que possam levar os estudantes ao estado de fluxo, a identificação do estado de fluxo, entre outros. Neste sentido, este trabalho tem o objetivo de apresentar à comunidade quatro desafios contemporâneos da Teoria do Fluxo aplicados a Informática na Educação.

\section{Introduction}

The application of Digital Information and Communication Technologies (DICT) in education has been receiving a crescent attention and it is gradually becoming a real leitmotiv for the teaching-learning process. In the last years, several countries have adapted their educational approaches in order to promote and support the use of 
computer-supported educational technologies in both physical and virtual learning contexts.

Currently, several researchers have been discussing about innovative teaching and learning methods and practices involving Computers in Education (Admiraal et al., 2011, Santos et al., 2014, Andrade et al., 2014). These methods and practices aims to provide students some behaviors as enthusiasm, engagement and motivation to perform some activity (Kirriemuir, J., and McFarlane, A. 2004). Therefore, these students can remain focused on the activities and, at the same time, produce a feeling of happiness and personal fulfillment during the activities. Such a feeling, according to Csikszentmihalyi (1975), may be called flow state and conforms a set of definitions which are currently known as Flow Theory.

Enthusiasm, engagement and motivation seem to be keywords when dealing with complex activities that demand a considerable amount of effort and dedication the learning activity, for instance. On the other hand, an research conducted by Getúlio Vargas Foundation in 2009, says 40\% of students between 15 and 17 years drop out because they find the school uninteresting - in other words, they fail to be motivated for proposed activities in school.

In this sense, it has been widely discussed by researchers how the Flow Theory could be applied to Education (Csikszentmihalyi, 1975; Csikszentmihalyi, 1990; Nakamura and Csikszentmihalyi, 2002; Rodriguez-Sanchez and Schaufeli, 2008). A slight literature review allow to affirm that individuals in flow state perceive their performance to be pleasurable and successful, and the activity being performed is perceived as worth doing for its own sake, even if no further goal is reached. Therefore, flow state is characterized as a deep immersion in an activity that is intrinsically enjoyable - for instance, when artists or athletes are focused on their play or performance.

In the educational context, the flow concept has been used by instructional designers, teachers, and managers (Admiraal et al., 2011). However, the authors above mentioned assume that a considerable amount of research remains to be done regarding to the use of Flow Theory in Computers in Education. Thus, this article has the goal of presenting and discussing some challenges related to the following research question: how Flow Theory in Computer-based influences educational activities? In order to present some insumes for this theme, four contemporary challenges will be presented in order to foster discussions about Flow Theory in Computers in Education.

\section{Background}

The following are some concepts on Flow Theory and Computers in Education.

\subsection{Flow Theory}

The notion of "flow" was introduced by Csikszentmihalyi (1975) as a technical term to describe the good feeling or "optimal experience" that people have as a motivating factor in their daily activities, such as at work, sports, and artistic performance (Faiola, A., et al. 2012). According to this author, the key to understanding flow is the concept of the "autotelic experience" (from the ancient Greek $\alpha$ vo $\tau \varepsilon \lambda \eta \dot{s, ~ o r ~ " s e l f ~ g o a l ") . ~ T h e ~}$ 
autotelic experience is the result of an activity or situation that produces its own intrinsic motivation, rewards, or incentives, specifically without any outside goals or rewards.

Since the establishment of the basis of Csikszentmihalyi's Flow Theory, several approaches has been made in order to describe this kind of experience. Csikszentmihalyi himself, in the year of 1990, described "Flow" in nine dimensions, which include: (1) clear goals, (2) immediate feedback, (3) a match between personal skills and challenges, (4) merger of action and awareness, (5) concentration on the task, (6) sense of control, (7) loss of self-consciousness, (8) altered sense of time, and (9) the experience of becoming "'autotelic".

Hoffman and Novak (1996) seek to summarize the dimensions proposed by Csikszentmihalyi (1990), proposing five required activities' measurements that lead to flow state: (1) enjoyment, (2) telepresence, (3) focused attention, (4) engagement, and (5) time distortion. Rodriguez-Sanchez and Schaufeli (2008) say that the previous dimensions could be simplified to just three key aspects that an activity must have to provide the flow state: (1) absorption, (2) enjoyment, and (3) intrinsic interest.

In general, all these authors summarize the flow state as mental state, located between anxiety and boredom. Figure 1 represents a simplification of Csikszentmihalyi's original flow model (Csikszentmihalyi's original flow model shows a more complete and complex view; however, for the sake of didactic purposes, the simplificate model will be used).

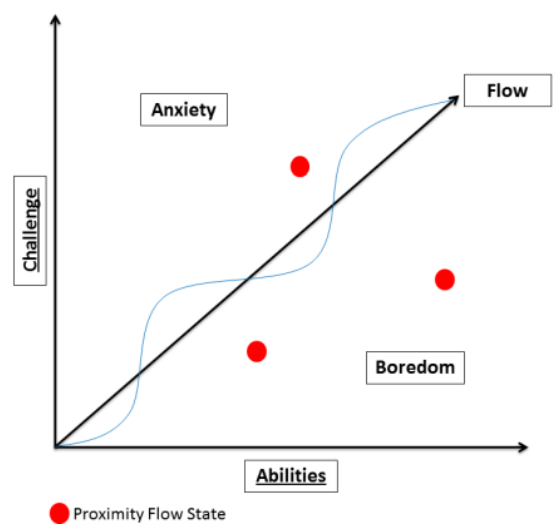

Figure 1: Identification of the Flow State (adapted from Csikszentmihalyi $(1990,1997)^{1}$

That is, for an activity to lead a person to the flow state, it is necessary to keep a balance between challenge's level and the ability of the person to complete that activity. If the difficulty of the challenge is greater than the person's skill level, he/she gets anxious. Otherwise, if the difficulty of the challenge is less than some individual's ability, it tends to be a boring activity (Admiraal et al.,2011).

\footnotetext{
${ }^{1}$ Original Csikszentmihalyi's flow model: [http://migre.me/pW94H]
} 


\subsection{Computers in Education - The role of digital games}

In an early paper, Baird (1991) already discussed about the prospects of Computers in Education, highlighting the trend of increased use of computers in the classroom by teachers and students. The use of computers in the classroom even exceeded the prospects of this author, and currently the topic "Computers in Education" have been discussed in many different aspects that transcend their use in face-to-face learning contexts.

The subject Computers in Education has been discussed in a very wide range of situations, one of them being the games-related ones. Researches vary from the application of digital games as a resource to support teaching and learning processes (Boutsika, E. 2014) to the use game elements as motivating factor in virtual learning environments (Hamari et al., 2014; Andrade et al., 2014)), or yet, to classify students from a gamified online learning environment according to their interactions (Paiva et al. 2015). However, it is noticeable that there is enough room to expand discussions in this perspective.

Flow Theory has gained space in these discussions; one possible reason for this, is a property of flow to keep the student focused on a given task, at the same time being motivated to perform the task (Faiola et al., 2012). In this context, Andrade et al. (2014), Hamari et al. (2014) and Lee et al. (2014), establish some discussions about the importance of Flow Theory applied to Computers in Education, specially developing computer-based activities capable of providing the flow state to students, as well, identify the flow state in students during computer-based activity.

\subsection{Related Works}

Andrade et al. (2014) propose a framework for Intelligent Tutoring Systems (ITS) development based on Flow Theory, aimed to increase student's motivation. The proposal consists on a framework that collaborates in the process and distribution of rewards and provides inputs for instructional dynamic design through personalization of learning objects.

Lee et al. (2014) present the results of an experiment using three models inspired by Csikszentmihalyi's theory for automatic detection of the optimal flow states, boredom and frustration, during the use of the ITS Tempranillo, in the field of Linear Algebra. The experiment was conducted with 78 students - 55 of them remained until the end of the study. The models were able to correctly identify $86 \%$ of the time in which students presented boredom, 64\% of the time in which the students were in the flow channel and $91 \%$ of the time in which users were frustrated.

Scoresby, J., \& Shelton, B. E. (2011) address the influence of Flow Theory in education; these authors investigate how this state is integrated with the way students learn, in particular, the investigation focuses on research in Virtual Learning Environments (VLE).

In this sense, this work's focus, unlike previous ones, is about isolated investigations, trying to investigate and discuss contemporary challenges of Flow Theory in the field of Computers in Education. 


\section{Challenge of Flow Theory in Computers in Education}

This item aims to present four challenges of Flow Theory applied to Computers in Education.

\subsection{Challenge 1: How to automatically identify the Flow State of a user based uniquely on their interactions}

Identify the flow state in people have been a major challenge for Flow Theory researchers. Initially, Csikszentmihalyi et al. (1977) were already facing a number of challenges to measure if a person was or not in flow state; during their research, they proposed different models for its identification.

Csikszentmihalyi and Csikszentmihalyi (1992) proposed two methods to identify if some individual are in flow state: open interviews and experience sampling. The latter method was administered as short questionnaires that participants filled out during an activity. According to Faiola et al. (2012), it required much effort from participants, e.g., carrying a device or downloading a software for entering feedback, or filling out a questionnaire at random times throughout the day. Because of this, other authors seek to use online questionnaires for obtaining the response and mapping the results. However, such work could not identify the flow state in real-time, in the moment when a student performs the computer-based activities.

In this sense, Andrade et al. (2014) point about the importance of automatic identification of flow state in real-time, in the moment that some student is performing a computer-based activity. In this scenario, it remains a challenge for researchers in Computers in Education, to identify the state flow of students in real time (Figure 1). While conducting computers-based activities, it would be possible for teachers, in a real-time basis, to identify if some student is already in flow state and if is not, how far he is to enter in such a state.

\subsection{Challenge 2: Reach the Flow State in computer-based activities}

Since the first research about Flow Theory, started by Csikszentmihalyi (1975), this concept has been discussed in many different aspects. One of the key aspects has been how to develop computer-mediated educational activities which are capable of providing the flow state to students (Csikszentmihalyi. et al. 1977; Moneta, 2012; Rathunde and Csikszentmihalyi., 2005). In this context, a series of studies have been developed in order to define a conceptual model for developing activities that could allow students to enter in flow state.

In this sense, Malone (1980) points out a sequence of five fundamental criteria that a computer-mediated activity must follow to induce students to reach the flow state: (i) the activity should be structured so that the player can increase or decrease the level of challenges faced, in order to exactly match personal skills with the requirements for action; (ii) it should be easy to isolate the activity, at least at the perceptual level, from other stimuli, external or internal, which might interfere with the engagement on it; (iii) there should be clear criteria for performance; a player should be able to evaluate how well or how poorly he is doing at any time; (iv) the activity should provide concrete feedback to the player, so that he could tell how well he is meeting the criteria of 
performance; and $(v)$ the activity ought to have a broad range of challenges, and possible several qualitatively different ranges of challenge, so that the player might obtain increasingly complex information about different aspects of her/himself.

Following a different perspective, Jones (1998) proposes eight fundamental characteristics of activity that involves some crucial points of Flow State: (i) tasks that can be completed; (ii) ability to concentrate on tasks; (iii) tasks with clear goals; (iv) tasks that provide immediate feedback; $(v)$ deep but effortless involvement (losing awareness of worry and frustration of everyday activity); ( $v i)$ exercising a sense of control over one's actions; (vii) concern for self should disappear during flow, but sense of self is stronger after flow activity; and (viii) sense of duration of time is altered.

This way, the main objective of these authors' researches was to develop activities which are capable of providing the flow state proposed by Csikszentmihalyi (1975) and Csikszentmihalyi (1990), which in summary emphasize that this state is located at a level between anxiety and the boredom (Figure 2), where boredom occurs when the activity is considered easy in comparison with the level of student skills, and the anxiety occurs when the difficulty level of activity is superior to the student's skill level. In this way the activity needs to be balanced according to the level of students skills, so that the student may to immerse in a flow state.

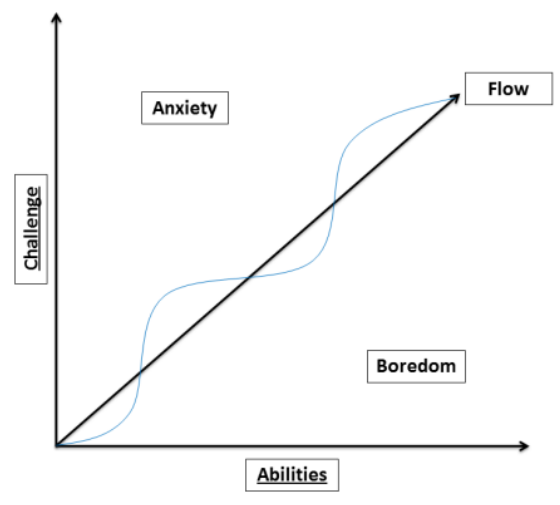

Figure 2: Model of flow (adapted from Csikszentmihalyi $(1990,1997)$

Following this line of thought, we present an alternative proposal for the challenge of develop educational computers-based activities that can provide the possibility of entering students in the flow state.

\subsection{Challenge 3: How to keep users in Flow State during the Implementation Life Cycle}

The definition of Csikszentmihalyi \& Csikszentmihalyi, (1992) asserts that the flow state has the objective of maintaining people involved in some activity. In this sense, the act of keeping someone in the flow state has been widely discussed, including in the context of educational technologies. Faiola et al. (2012) discuss the difficulty to propose tasks that allow students remain in Flow while conducting activities in virtual environments. These authors argue that the key to understand flow is the concept of the "autotelic" experience. 
Novak et al. (1998) determined that having a time limit for user interaction increases the challenge and results in more focused attention on the problem by the participant. This induces the student to keep in flow state during the proposed activity. On the other hand, Admiraal et al. (2011) point out that flow activities, including intellectually demanding tasks, can also be enjoyable and satisfying. They may provide a feeling of creative accomplishment and satisfaction, also promoting the flow state for a longer period of time (Figure 3).

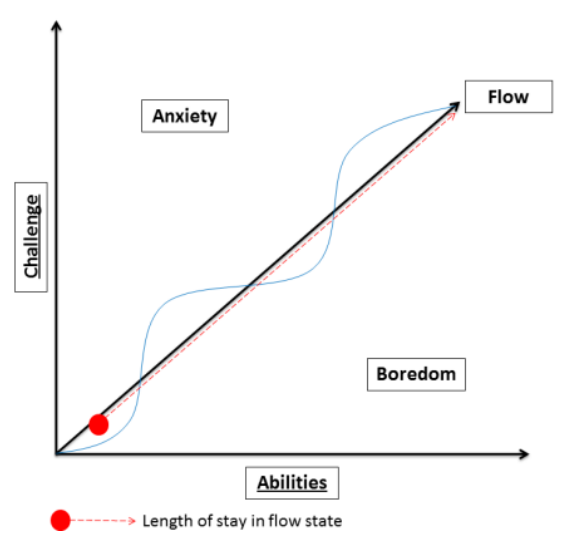

Figure 3: Sojourn (temporary permanence) in Flow State

Considering the discussions here addressed, it is still a huge challenge for researchers in Computers in Education to propose activities, which in addition to facilitate students enter into flow state, also allow it to remain in flow state during the activity.

\subsection{Challenge 4: Which Flow Theory models are more adequate to Computer- based Education}

Throughout the research on Flow Theory, different conceptual models have been proposed by Csikszentmihalyi (1975), Schell (2008) and Sala (2013). These authors seek to understand how the flow state works and how an activity can lead to this state. Csikszentmihalyi (1975) propose the flow as an emotional state located between anxiety and boredom. For this author, this state has not variations of "level" (Figure 4). Schell (2008) instead, proposes a relatively different model, pointing out that the state of flow is not continuous, and variations within the state itself may occur, pushing the person out of the flow of state during an activity (Figure 5). Lastly, Sala (2013) addresses the flow as a state divided in different modules (worlds), each one located in a different slice of time, being possible to present variations in the level of immersion inside each slice (Figure 6). 


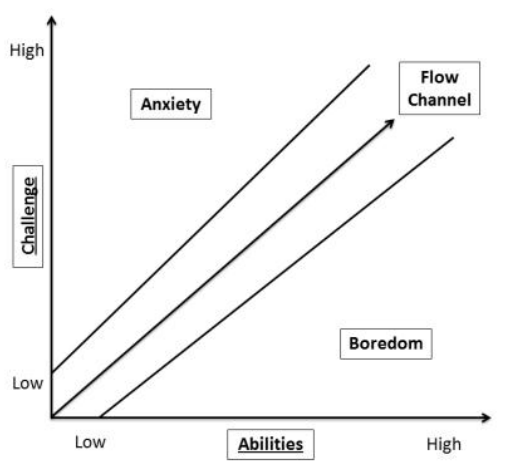

Figure 4: Model of Csikszentmihalyi

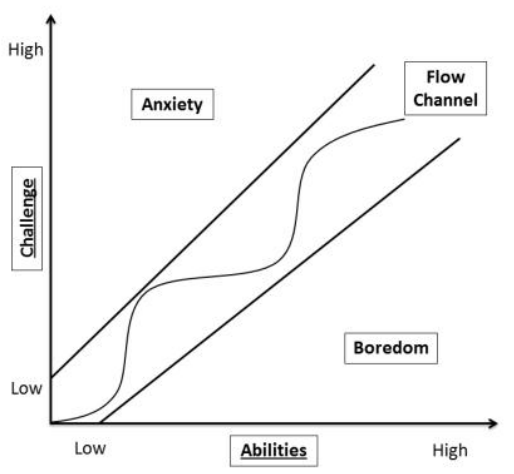

Figure 5: Model of Schell

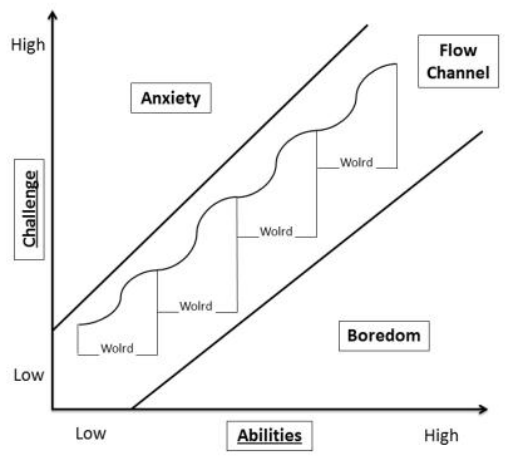

Figure 6: Model of Sala

However, so far none of these models is considered a consensus among researchers, which becomes a challenge to define which of these models is more effective in the field of Computers in Education. In this sense, an important challenge to Flow Theory as a whole (not only the Flow Theory applied to Computers in Education) is to define which model - or which combination of them - is more suited to represent the reality and therefore be used as a reference representation mode.

\section{Concluding Remarks}


This work present four challenges of Flow Theory applied to the Computers in Education field. The challenges presented are concerned with: developing computersbased activities capable of carrying the students to flow state; how to remain there; how to automatically identify the flow state of the user based on their interactions; and the definition of the most suitable flow model for use as a reference model.

The challenges discussed could collaborate with the field of Computers in Education, especially for the development of activities that could lead students to the a state of motivating actions like the Flow State, as well as identifying students' flow states while using virtual learning environments, for instance.

Currently, the authors of this article, are performing a meta-analysis for identification of empirical results about the data provenient from the identification of flow state in students in computer-based activities. As a future work, it is being proposed the development and validation of a model to identify the flow state in virtual learning environments, as well as to suggest other challenges that could be discussed by the academic community, leading to possible development of computational solutions for them.

\section{Acknowledgment}

This work was supported in part by Brazilian Coordination for the Improvement of Higher Education Personnel (CAPES).

\section{References}

Admiraal, W., Huizinga, J., Akkerman, S., \& Ten Dam, G. (2011) "The concept of flow in collaborative game-based learning". In: Computers in Human Behavior, 27(3), 1185-1194.

Andrade, F. R. H., Challco, G. C., Isotani, S. (2014) "Em Direção a Gamificação de Sistemas Tutores Inteligentes: Aplicando a Teoria do Fluxo no Design Instrucional de Canários Colaborativos de Aprendizagem". In: Congress of the Brazilian Computer Society (Vol. 1, pp. 700 - 709). Brasilia-DF.

Baird, B. (1991) "Perspectives on computers in preservice science teacher education". ACM SIGCUE Outlook, 21(1), 5-16.

Csikszentmihalyi M. (1990) "Flow: The psychology of optimal experience”. New York: Harper-Collins.

Csikszentmihalyi, M. (1975) "Beyond boredom and anxiety". Jossey-Bass Publishers. pp. 10-. ISBN 978-0-7879-5140-5. Retrieved 10 November 2013.

Csikszentmihalyi, M., \& Csikszentmihalyi, I. S. (1992) "Optimal Experience: Psychological Studies of Flow in Consciousness". Cambridge University Press.

Csikszentmihalyi, M., Larson, R., \& Prescott, S. (1977) "The ecology of adolescent activity and experience". Journal of Youth and Adolescence, 6, 281-294.

Faiola, A., Newlon, C., Pfaff, M., \& Smyslova, O. (2013) "Correlating the effects of flow and telepresence in virtual worlds: Enhancing our understanding of user 
behavior in game-based learning". Computers in Human Behavior, 29(3), 11131121.

Fundação Getúlio Vargas - FGV. (2009) "Motivos da Evasão Escolar". Available in: http://www.cps.fgv.br/cps/tpemotivos/ Accessed May, 18th, 2015.

Hoffman, D. L., \& Novak, T. P. (1996) "Marketing in hypermedia computer-mediated environments: Conceptual foundations". Journal of Marketing, 60(2), 50-68.

John Kirriemuir, Angela Mcfarlane. "Literature Review in Games and Learning". A NESTA Futurelab Research report - report 8. 2004. 〈hal-00190453>.

Jones, M. G. (1998) "Creating engagement in computer-based learning environments". Retrieved April, 12, 2001.

Lee, P., M., Jheng, S., Y., \& Hsiao, T., C. (2014). "Towards Automatically Detecting Whether Student Is in Flow". In S. Trausan-Matu, K. E. Boyer, M. Crosby, \& K. Panourgia (Eds.), Intelligent Tutoring Systems (pp. 11-18). Springer.

Malone, T (1980) "What Makes Things Fun to Learn? A Study of Intrinsically Motivating Computer Games". Palo Alto: Xerox .

Moneta, G. B. (2012) "On the measurement and conceptualization of flow". In S. Engeser (Ed.), Advances in flow research (pp. 23-50). New York: Springer.

Nakamura, J., \& Csikszentmihalyi, M. (2002) "The concept of flow". In: C. R. Snyder \& S. J. Lopez (Eds.), Handbook of positive psychology(pp. 89-105). Oxford: Oxford University Press.

Paiva, R. O. A., Bittencourt, I. I., da Silva, A. P., Isotani, S., \& Jaques, P. (2015) "Improving Pedagogical Recommendations by Classifying Students According to their Interactional Behavior in a Gamified Learning Environment". In: Proceedings of the ACM Symposium on Applied Computing.

Rodriguez-Sanchez, A. M., \& Schaufeli, W. B. (2008) "Flow experience among information and communication technology user". Psychological Reports, 102, 2939.

Sala, T. (2013) "Game Design Theory Applied: The Flow Channel". Available on the Internet at <http://tinyurl.com/SalaFlowApplied >. Accessed May, 19th, 2015.

Santos, W. O., Silva, A. P., \& Silva Junior, C. G. (2014) “Conquistando com o Resto: Virtualização de um Jogo para o Ensino de Matemática”. In: Proceedings of Brazilian Symposium on Computers in Education (Vol. 25, No. 1, pp. 317-321).

Scoresby, J., \& Shelton, B. E. (2011) "Visual perspectives within educational computer games: effects on presence and flow within virtual immersive learning environments". Instructional Science, 39(3), 227-254. 